\title{
Impact of a theory based intervention to increase bicycle helmet use in low income children
}

\author{
Sherry Garrett Hendrickson, Heather Becker
}

\begin{abstract}
Objective-While community interventions to increase bicycle helmet use have increased markedly, few of these studies are theoretically based. The purpose of this study was to determine relationships among PRECEDE model predictors and self reported helmet use among 407 fourth graders from nine low income, non-urban schools.

Setting-Low income schools, with high minority populations in eight nonmetropolitan Central Texas counties were chosen.

Methods-Schools were randomly assigned in a repeated measures design to either classroom only, parent-child, or control groups. School nurses were educated by the researchers to present a head injury prevention program in all but the experimental schools. Researchers made contact by phone with the parents of children in the parent-child group.

Results and conclusions-Participation in either of the educational interventions, followed by belief that helmets protect your head (a predisposing factor), and participation in the parent intervention condition, added significant unique variance to the prediction of helmet use after helmet ownership is accounted. These four variables, taken together, account for $72 \%$ of the variance in predicting bicycle helmet use.
\end{abstract}

(Injury Prevention 1998;4:126-131)

Keywords: PRECEDE model; head injury prevention; theory based intervention; bicycle helmets

As research funding grows ever more scarce, and health care strains to support long term care for injured patients, programs to prevent traumatic brain injury are increasing. Children younger than 15 years old account for $71 \%$ of all cyclist morbidity, and $33 \%$ of all bicyclist related deaths, despite the fact that children represent only $40 \%$ of cyclists. ${ }^{1}$ Bicycle helmets are known to decrease risk of head injury by $74-85 \% .^{2}$ This fact, however, may be unknown to today's parenting generation, who, as children, rode without helmets.

Because bicycle helmet use is an effective deterrent to head injury, numerous worldwide efforts, ${ }^{3}$ many presented at the International Conference on Helmet Initiatives, ${ }^{4}$ have been undertaken to educate the public about the importance of bicycle helmet use and to make bicycle helmets more accessible. However, a theoretical base underlying these interventions is notably lacking.

A popular evaluation model used in health education and injury prevention, and highlighted at the International Conference on Helmet Initiatives, is PRECEDE. This model identifies predisposing, enabling, and reinforcing educational factors surrounding an intervention. Predisposing factors include knowledge, attitude, beliefs, values, and perceptions that provide the motivation for behavior. Enabling factors support a desired behavior change (for example, helmet ownership, as requisite for helmet use). Reinforcing factors provide reward, incentive, or punishment for a behavior to be perpetuated or terminated. These components of the model are considered antecedents to behavioral change and were implemented in the intervention and the assessment of the intervention described in the present study.

Empirical evidence suggests that various interventions have increased helmet use, ${ }^{5-7}$ yet knowledge of the specific combination of factors most predictive of helmet use is limited, ${ }^{89}$ as is a clear theoretical basis. Hierarchical multiple regression was used in the present study to predict bicycle helmet use as an outcome of a school based program, guided by the PRECEDE model. ${ }^{10}$ The study addressed the following research question: How much do predisposing, enabling, reinforcing factors (as identified in the PRECEDE model), and participation in an educational intervention, add to the prediction of reported bicycle helmet use, after controlling for helmet ownership?

Over 600 published applications of the PRECEDE model for health promotion planning had appeared by $1997 .{ }^{11}$ In one of only two helmet studies found using the PRECEDE framework, ${ }^{912}$ persuasive communication, community organization, the joint use of traditional educational and reinforcing activities, and the enabling factor of increasing helmet access, boosted use by $23 \% .^{9}$ The program targeted elementary age students, 5 to 12 years old, in one region in Quebec. Before and after program helmet use was observed at three sites in poor and average rich areas of the municipality. In comparison, our nine community study included a control group, and focused on the age group of 10-12 year olds who are at highest risk for bicycling related morbidity and mortality. ${ }^{13}$

\section{Method}

A multiple regression model was employed to determine how much variance in children's self
Correspondence to: Sherry Garrett Hendrickson.
University of Texas at 78701, USA

S Garrett Hendrickson 
Table 1 Correlation between PRECEDE model variables, intervention conditions, demographics, and self reported helmet use

\begin{tabular}{|c|c|c|c|}
\hline Predictor variables & $\begin{array}{l}\text { Time 1: helmet use } \\
\text { before intervention } \\
(n=384)\end{array}$ & $\begin{array}{l}\text { Time 2: helmet use } \\
\text { immediately after } \\
\text { intervention }(n=363)\end{array}$ & $\begin{array}{l}\text { Time 3: helmet use } 1 \\
\text { month after } \\
\text { intervention }(n=351)\end{array}$ \\
\hline \multicolumn{4}{|l|}{ Intervention conditions } \\
\hline Parent and classroom & $-0.101^{\star}$ & $-0.483^{\star \star \star}$ & $-0.388^{\star \star \star}$ \\
\hline Control group & 0.072 & $0.483^{\star \star \star}$ & $0.329^{\star \star \star}$ \\
\hline Classroom only & 0.034 & 0.040 & 0.077 \\
\hline \multicolumn{4}{|l|}{ Demographics } \\
\hline Ethnicity: $1=$ whites $(188) ; 2=$ other $(142)$ & $-0.131^{\star \star}$ & $-0.123^{\star \star}$ & -0.053 \\
\hline Gender: $1=$ boy; $2=$ girl & -0.004 & -0.024 & 0.016 \\
\hline Helmet ownership ( $1=$ yes owns; $2=$ no) & $-0.257 \dagger$ & $-0.838 \dagger$ & $-0.679^{\star \star \star}$ \\
\hline \multicolumn{4}{|l|}{ Predisposing factors } \\
\hline A helmet doesn't protect your head & 0.030 & -0.044 & 0.000 \\
\hline Very bad head injuries can change you forever & -0.051 & 0.020 & $0.105^{\star}$ \\
\hline I can control my bike so well that I will not be hurt & 0.034 & 0.076 & 0.094 \\
\hline Whether or not you get hurt in a bike accident is just a matter of luck & 0.036 & -0.039 & 0.023 \\
\hline If someone has a bad head injury they will be back at school or work in a few days & -0.035 & -0.099 & 0.002 \\
\hline \multicolumn{4}{|l|}{ Enabling } \\
\hline I see bicycle helmets or advertisements for bicycle helmets in the stores & $0.105^{\star}$ & $0.138^{\star \star}$ & 0.084 \\
\hline Helmets cost too much & -0.053 & 0.000 & 0.046 \\
\hline \multicolumn{4}{|l|}{ Reinforcing } \\
\hline Mom is the one person who most often says you should wear a helmet & $0.111^{\star}$ & $0.226 \dagger$ & $0.172^{\star \star \star}$ \\
\hline Do you personally know someone who has had a bad head injury? & -0.085 & 0.054 & -0.002 \\
\hline
\end{tabular}

${ }^{\star} \mathrm{p}<0.05 ;{ }^{\star \star} \mathrm{p}<0.01 ;{ }^{\star \star \star} \mathrm{p}<0.001 ; \mathrm{tp}<0.0001$

Note: Dependent variable, helmet use, is self reported by children. In parent-child condition, parent reported per cent of child's helmet use did match their child's self report $(18 \%)$. Variable coded dichotomously as yes/no for helmet use: $1=y e s ; 2=$ no. All predictors except helmet use and assignment to intervention condition measured preintervention. Of the 330 students who completed questionnaires at all three times 188 self identified as white, 89 as Hispanic, and 17 as black.

reported bicycle helmet use was accounted for by predisposing, enabling, and reinforcing factors. This included an intervention delivered to fourth grade students by their school nurse.

\section{SAMPLE RECRUITMENT AND DESCRIPTION}

Setting selection: the rural setting was chosen because rapid access to trauma services is not always available making prevention of injury even more important. ${ }^{14}$ This report recommended that future interventions include: training of rural health care providers (thus our inclusion of school nurses) and oversampling of racial and ethnic minorities, with inclusion of low socioeconomic status. We made low income schools and minority representation key criteria.

School nurses who attended a professional meeting and indicated interest in this project were sent letters explaining the study. Each nurse agreed to teach two classes on bicycle helmet use and basic bicycle safety, and to administer student questionnaires. These educational materials then became the property of each participating school. Free helmets were promised to an equal percentage of the participating students at each school and discount coupons for all students. Principals were asked to send a cover letter with the parental consent forms, which were provided in both English and Spanish.

\section{STUDENT RECRUITMENT}

Although Spanish language versions of materials were available, all children completed the questionnaires in English as teachers advised that the students were bilingual. An assent form was provided to all children. In addition to consenting to have their children involved, all parents with children in the classroom and a parent intervention group were asked to agree to be interviewed twice by telephone.

INSTRUMENTATION

An instrument was developed based on concepts of the PRECEDE model (table 1). Chil- dren were asked to indicate their sex, ethnicity, whether or not they rode a bicycle, or owned a helmet. The children's instrument consisted of 31 items. A three point scale (yes, no, or not sure) was used for most items, excluding knowledge items. The dependent variable, helmet use, was measured by the children's response to the question, "do you use a bicycle helmet?".

\section{PILOT TESTING}

Experts with experience in using the PRECEDE model, working with school age children and community research reviewed the questionnaire initially and their recommendations for refinement were implemented. Reading level of the instrument was assessed and determined to be at sixth grade level and, was then simplified further. To enhance the reliability and validity of the intervention and data collection, two pilot studies preceded this study. In the first pilot, a rural school granted permission to pilot the bicycle helmet classroom presentation and children's questionnaire. This involved 100 fourth through eighth grade students. From that pilot, it was decided the youngest students were the most receptive to helmet use.

The second pilot was undertaken to refine the data collection instruments. Sixty fourth graders from another rural school answered questionnaires without the classroom helmet presentation, although an educational session was made available to the district school nurse after the pilot. The contact with parents by phone was piloted with 30 parents. As a result, the language in the children's questionnaire was simplified. Parental inclusion criteria were expanded to include fathers, and the length of the telephone interview was shortened.

\section{NURSES PROGRAM ORIENTATION}

Participating nurses attended a four hour training course to discuss the helmet classroom intervention. Program materials were developed by a large southwestern hospital. A 
$\$ 50.00$ stipend for the nurses time and travel to the training site were provided. Overhead transparencies were given to each nurse with the classroom education content in an outline form, and a video of interviews with young brain injured adults. Posters, child oriented factsheets, and helmet reminder stickers were provided for each fourth grader. Nurses were asked to identify anticipated support and potential barriers in their settings. A total of 333 helmets were given out.

\section{CHILDREN'S INTERVENTION}

The nine participating schools were randomly assigned to the three intervention conditions. These conditions included: a classroom intervention group, a classroom intervention with parental telephone intervention, and the control group, who received neither intervention. In these three control schools, school nurses administered questionnaires on the same timetable as distributed in the intervention schools.

In the first session for the six intervention schools, the pretest was administered, followed by the nurse's introduction of the video. At the end of the video there was a brief discussion of how a head injury might change a person's life. Helmets were then distributed.

At the second class, nurses referred to the video and asked students how a head injury could change their lives. Content included the three most frequent causes of bicycle crashes for this age group, basic pathophysiology of the brain, and demonstration of correct helmet use. Nurses were encouraged to have students practice refuting derisive peer comments. One creative nurse obtained a cow brain from the local slaughterhouse to demonstrate its fragility. Another nurse used Jello in an individual, plastic encased serving, dropped from a fourth grade student's height, to demonstrate head injury. Questionnaires were distributed after the discussion. Take home handouts were also provided.

The last administration of questionnaires took place approximately one month later, with no program content. At the conclusion of the program, the three control group schools had the option of presenting the helmet program to their students. Research staff were present at all classroom presentations.

HELMET DISTRIBUTION

Funding allowed helmets for $60 \%$ of participating students to be awarded through a drawing at each school. In several schools, however, nurses sought community involvement to provide additional helmets for all participating students. Students who did not receive a helmet through the drawing were eligible to purchase one through use of a coupon. In the control schools, helmets were withheld from distribution until after the third administration of the questionnaire. One nurse at a control school did make helmets available after the second data collection, however, due to her concern for the children's safety.
PARENTAL INTERVENTION

Previous studies have documented the importance of parental influence on children's safety behaviors. ${ }^{15-18}$ Reinforcement, potentially provided by parents, is considered essential to sustained behavior in the PRECEDE model. Telephone calls were timed to coincide with children's first educational session, and assessed parents' attitudes toward bicycle safety. Information provided encouraged parental reinforcement of the bicycle safety information their children received at school. In the classroom only intervention, solicitation of parental involvement was limited to a take home work sheet. Further, both groups were sent letters developed by the researchers, on school stationery, and signed by the school nurse and principal. These letters in English and Spanish, focused on bicycle related head injury.

\section{Results}

\section{STUDENT'S RESPONSE RATE}

Because class size varied across the nine schools, the number of children in each intervention condition also varied. There were 163 children in the classroom only condition, 142 children in the parental intervention group, and 102 in the control group. This totaled 407 students, $37 \%$ of the 1090 children originally invited to participate. A total of 329 $(81 \%)$ completed all three data collections.

\section{SAMPLE DESCRIPTION}

Among the 391 students who completed the first questionnaires, approximately $27 \%$ were Hispanic, $57 \%$ white, and $5 \%$ black. Males made up $47 \%$ of the sample. Overall, approximately $18 \%$ owned helmets before the intervention, a number corroborated by parent telephone interviews. About $96 \%$ of respondents rode bicycles, but only 3\% rode to school. Most children rode school buses from outlying areas. Children who did not ride bicycles were eliminated from subsequent analysis. Family income, available only for those in the parent contact group, was less than $\$ 15000$ per year for $23 \%$, and for $50 \%$ it was less than $\$ 25000$.

On average, $25 \%$ of students in the six experimental schools reported helmet use before the intervention, compared with $17 \%$ in the three control schools. Despite the misplacement of helmets, and resulting delay of children having helmets at time 3 in one school, there was still an overall 55\% increase in the intervention schools, compared with a $16 \%$ increase in the control schools. This $16 \%$ increase is attributed in part to the early distribution of helmets in one of the control schools before time 3 .

\section{BIVARIATE CORRELATIONS}

The bivariate correlations between intervention, demographic, and PRECEDE model variables, and self reported helmet use were collected before the intervention, immediately after the intervention, and one month later (table 1). Skewed distributions for many variables resulted from the children's tendency 
Table 2 Hierarchical regression to predict bicycle helmet use

\begin{tabular}{|c|c|c|c|c|c|}
\hline Regression step & Variable & Multiple $R$ & Adjusted $R^{2}$ & Beta weight & Significance \\
\hline Step 1 & Helmet ownership & 0.838 & 0.70 & 0.76 & 0.000 \\
\hline \multirow{3}{*}{ Step 2} & Belief helmets protect your head & 0.845 & 0.71 & -0.11 & 0.000 \\
\hline & Being in control $v$ intervention & 0.847 & 0.72 & 0.08 & 0.019 \\
\hline & Being in parental intervention $v$ not in parental intervention & 0.850 & 0.72 & -0.07 & 0.039 \\
\hline
\end{tabular}

$\mathrm{F}$ for total equation $=217.71, \mathrm{p}<0.0001, \mathrm{df}=4 / 332$.

Beta weights taken from last step of regression equation.

to answer affirmatively to everything and may contribute to the low correlations. Dummy variables were created to represent minority group status and participation in each intervention condition. These variables were participation in either intervention versus control group, and the parent/child intervention versus the control group or the classroom only group. Bicycle helmet use was represented as a dichotomous variable, with a value of " 1 " indicating that the student reported using a helmet and a " 2 " if the student circled no for this question.

While some correlations were statistically significant because of the large sample size, only those related to helmet ownership or participation in the intervention met Cohen's criteria for moderate effect size $(r>0.30) .{ }^{19}$ Participation in the parent-child treatment was significantly correlated with self reported helmet use immediately after the second intervention $(r=-0.483, \mathrm{p}<0.001)$ and one month later $(r=-0.388, \mathrm{p}<0.001)$. Equally, but inversely correlated, was participation in the control group. Helmet ownership immediately after the intervention had a still greater correlation with self reported helmet use immediately after the intervention $(r=-0.838, \mathrm{p}<0.0001)$ and one month later $(r=-0.679, \quad \mathrm{p}<0.001)$. Other correlations were small. For example, the reinforcing variable of mother encouraging helmet use was correlated with helmet use immediately after the intervention at $r=0.226(\mathrm{p}<0.0001)$.

\section{HIERARCHICAL REGRESSION}

Hierarchical multiple regression was used to predict the dichotomous variable, self reported bicycle helmet use immediately after the educational intervention (time 2 data collection). The research question addressed by this analysis was: How much do predisposing, enabling, reinforcing factors (as identified in the PRECEDE model), and participation in an educational intervention, add to the prediction of reported bicycle helmet use, after controlling for helmet ownership? Twelve variables were selected for possible inclusion as predictor variables, based on their potential importance as factors identified in the PRECEDE model and their bivariate correlations with helmet use. Assuming that helmet ownership at the conclusion of the intervention (either through helmet distribution as part of the intervention or through prior ownership) would be strongly related to helmet use, we entered this enabling factor on the first step, to control for its effects. As expected, helmet ownership was highly correlated with helmet use $(r=0.838,1 / 325 \mathrm{df})$. Of the other 12 predictors available for stepwise entry into this equation, three of them-participation in either of the educational interventions, followed by belief that helmets protect your head (a predisposing factor), and participation in the parent intervention condition-added significant unique variance to the prediction of helmet use. An examination of residual plots suggested assumptions underlying regression analysis were not seriously violated.

As shown in table 2, the four variables that entered the equation accounted for $72 \%$ of the variance in predicting helmet use for the fourth grade participants. Thus, while helmet use is strongly related to helmet ownership, participation in an educational intervention (particularly one involving parents), and beliefs about helmet efficacy, were associated with even higher reported use of bicycle helmets.

\section{Discussion}

This study investigated relationships among components of the PRECEDE model ${ }^{10}$ and self reported helmet use in low income fourth grade students from eight non-metropolitan sites. A hierarchical regression model determined that $72 \%$ of the variance in self reported helmet use was explained by the combination of the intervention and PRECEDE variables. Although no reinforcing factors entered the equation, bringing the message through a community member (the school nurse), and directly contacting parents, was undeniably valuable.

The PRECEDE model argues for assessing the epidemiological and social sources of a problem, in this case, head injuries related to lack of helmet use. Consequently, we chose a setting and population largely neglected-low income children living outside metropolitan areas. Beyond providing access to helmets across a peer group, participating schools now have program materials.

As expected, helmet ownership was strongly related to self reported helmet use, accounting for $70 \%$ of the variance. Clearly, children who don't have helmets can't use them, so helmet distribution is an important ingredient of these intervention programs, especially in low income areas where even reduced helmet cost may be problematic. However, our results suggest that an educational intervention that addresses beliefs about helmet efficacy can maximize the impact on children's bicycle helmet use. While public funds are not always available to support helmet distribution, nurses in some of the communities demonstrated that private funding can help fill the gap. In addition, this state's medical association auxiliary has contributed helmets to various communities in need. 
Both intervention conditions included the predisposing element of motivating change through the child's attitude, beliefs, perceptions, and knowledge base. As demonstrated in the regression analysis, the parent-child condition was the most successful of the intervention conditions, contributing significant unique variance over and above the contribution made by participation in the classroom only intervention.

While children can be reached through schools to provide information that expands their health choices, both educators and the health care team are often frustrated by their inability to reach low income families. ${ }^{9}{ }^{20}{ }^{21}$ Our finding that students in the parent-child intervention reported greater helmet use suggests it is worth the effort to approach the health education of children, not only in peer units, but in ways that involve parents, and to do so with a theoretical basis.

The PRECEDE model recommends a diagnostic study to assess which variable requires intervention. While few of the variables representing components of the PRECEDE model were significantly correlated with helmet use in this study, this lack of relationship may have been related, at least in part, to measurement issues. Most students endorsed certain items (for example: I can get a bicycle helmet), resulting in skewed responses on these items. In turn, these items did not contribute to the prediction of helmet use. Future studies should investigate alternative measurement assessment strategies.

Gender was not contributory to the predictive model, despite the fact that boys are injured twice as often as girls, dying of these injuries five times as often. ${ }^{122}$ No gender difference was noted in two observational studies of school age child participants of helmet programs,${ }^{69}$ although studies indicate that males have greater morbidity and mortality related to lack of helmet use at all ages. ${ }^{23}{ }^{24}$ The fact that intervention effectiveness did not differ by gender is encouraging, because it suggests that at least in this study, boys, who are at greatest risk for injury, may be as receptive as girls to this type of educational intervention. It remains to be seen if both boys and girls maintain helmet use over the long term, when other factors, such as peer pressure, may become more influential.

While ethnicity of children participating in a helmet program has not been correlated with any program's success or failure, this factor should be a consideration because of the overrepresentation of minority children in injury statistics. ${ }^{25}$ Our study found a small relationship between ethnicity and self reported helmet use (table 1). This relationship merits further investigation. Although gender, age, family size, and income were originally considered in the PRECEDE model as predisposing factors, they are now considered separately from those predisposing factors on which programs can directly impact. ${ }^{26}$

Those who chose to participate (or agree to have their children participate) may have been those most receptive to the intervention, resulting in sampling bias and uncertainty of the generalizability of these findings. That $63 \%$ of the students invited to participate declined, limits the generalizability of results. Some students that had parental consent did not sign their assent forms. Some schools offered children the more attractive offer for outdoor play rather than keeping with the research team's alternative of a crossword puzzle. Further, helmet wear has, for many, become a personal freedom issue, especially evident in legislative efforts. In the parent intervention, a common comment was that being rurally located, there was less need for helmets because of the frequency of riding on their own land, and helmets were more for rides near heavy traffic. Finally, we know that poverty was a reality for children, who may ride bikes, but likely do not have bikes of their own. Paraphrasing one parent, "I don't want him thinking he can get a bike, just because he has a helmet".

Another concern centers around use of children's self reported helmet use. Due to the rural setting, direct observation of helmet use was not possible. These rural communities, did not, for the most part, have designated bicycle paths, sidewalks, or even parks in neighborhoods where bicycle riding was concentrated. Parkin and colleagues caution against the dangers of observational sampling bias in bicycle helmet use, ${ }^{21}$ while other researchers support the use of observational helmet studies. ${ }^{927}$ Self report of helmet use are subject to factors such as social desirability and faulty memory.

Our study measured reported helmet use immediately after acquisition of helmets by most children in the study. Maintenance of helmet use as an incorporated health behavior may be more appropriately accessed during the next school year. Additional research is needed to monitor ongoing helmet use, within the context of the predisposing, enabling, and reinforcing factors identified in the PRECEDE model. The model would predict that the reinforcing factors (social support) which are so important in the short term as demonstrated here would gradually become internalized. Expansion of PRECEDE to include the concept of policy regulating or resourcing, and organizing, PROCEED ${ }^{28}$ further emphasizes addressing multifactorial health risks, such as bicycle related head injury, with multisectorial efforts.

Perhaps the true success of our study is in the process of reaching children and their parents who experience economic and resource isolation. Improved intervention models should build on this knowledge in an effort to bridge the gap currently evident in prevention efforts and outcomes to reach those most in need.

This report was funded by the Centers for Disease Control, and graciously awarded to the researchers through the Texas Office of Prevention of Developmental Disabilities. The investigators gratefully acknowled the gratefully acknowledge the assistance of the staff at the Center for Health Care and Research Evaluation at the University of Texas at Austin School of Nursing in the conduct of this project, particularly Leigh Shaver, May Dobal, Pi-Chen Chang, Mellissa Mackey, Daira Munn, and Pat Trcka. Additional thanks to the National Resource Center for Cultural Competency for time and effort in translation of consent forms and handouts. 
1 US Consumer Product Safety Commission. Bicycle helmet facts. Washington, DC: US Government, 1994.

2 Thompson RS, Rivara FP, Thompson DC. A case-control study of the effectiveness of bicycle safety helmets. $\mathrm{N} \mathrm{Engl} \mathrm{F}$ Med 1989;320:1361-7.

3 Hag S, Becker L, eds. The international conference on bicycle helmet initiatives final report. Third International Conference on Injury Prevention and Control, Melbourne, ence on Injur
Australia, 1996.

4 World Health Organization and Commonwealth Department of Human Services and Health. Helmet initiativeglobal coordination to bring about local action. Third International Conference on Injury Prevention and Control, Melbourne, Australia, 1996.

5 Rivara FP, Thompson DC, Thompson RS, et al. The Seatthe Children's Bicycle Helmet Campaign: changes in helmet use and head injury admissions. Pediatrics 1994;93 567-9.

6 Liller KD, Kent EB, Knowles A, et al. Promoting use of bicycle helmets among children: a school and communitybased effort. 7 Health Educ 1995; 26:173-7.

7 McEvoy M. Increasing bicycle helmet use among schoolage children. Nurse Practitioner: American fournal of Primary Health Care 1996; 21:150-1.

8 Otis J, Lesage D, Godin G, et al. Predicting and reinforcing children's intentions to wear protective helmets while bicycling. Public Health Rep 1992;107:283-9.

9 Farley C, Haddad S, Brown B. The effects of a 4-year program promoting bicycle helmet use among children in Quebec. Am f Public Health 1996;86:46-51.

10 Green LW, Kreuter MW, Deeds SG, et al. Health education planning: a diagnostic approach. Palo Alto, CA: Mayfield Publishing, 1980.

11 Ratner PA, Green LW, Frankish CJ, et al. Setting the stage for health impact assessment. Fournal of Public Health Policy 1997; 108:67-79.

12 Jones CS, Macrina D. Using the PRECEDE model to design and implement a bicycle helmet campaign. Wellness Perspectives: Research, Theory and Practice 1993;9:68ness.

13 National Committee for Injury Prevention and Control. Injury prevention: meeting the challenge. New York: Oxford University Press, 1989. (A supplement to Am F Prev Med 1989;5(3).)

14 United States Congress Office of Technology Assessment.
Adolescent health - volume III: crosscutting issues in thedelivery of health and related services. OTA-H-467. Washington, DC: US Government Printing Office, 1991.

15 Russel KM, Champion VL. Health beliefs and social influence in home safety practices of mothers with preschool children. Image f Nurs Sch 1996;28:59-64.

16 Lau RR, Quadrel MJ, Hartman KA. Development and change of young adults' preventive health beliefs and behavior: influence from parents and peers. 7 Health Soc Behavior: influence from

17 Peterson L, Bartelstone J, Kern T, et al. Parents' socialization of children's injury prevention: description and some initial parameters. Child Dev 1995;66:224-35.

18 Page RM, Follett TK, Scanlan A, et al. Perceived barrier, risk perception, and social norm attitudes about wearing helmets among college students. Am f Health Behav 1996; 20:33-40.

19 Cohen J. Statistical power analysis for the behavioral sciences. Hillsdale, NJ: Lawrence Erlbaum Associates, 1988.

20 Schneider ML, Ituarte P, Stokols D. Evaluation of a community bicycle helmet promotion campaign: what works and why. Am f Health Prom 1993;7:281-7.

21 Parkin PC, Spence LJ, Hu X, et al. Evaluation of a promotional strategy to increase bicycle helmet use by children. Pediatrics 1993;91:772-7.

22 Henderson M. The effectiveness of bicycle helmets: a review. BHSIDOC\#586. New South Wales, Australia: Motor Accident Authority of New South Wales, 1995.

23 Thompson DC, Rivara FP, Thompson RS. Effectiveness of bicycle safety in preventing head injuries. $\mathcal{F} A M A$ 1996;276: 1968-79.

24 Insurance Institute for Highway Safety. Fatality facts 1997: bicycles. Arlington, VA: IIHS, 1997.

25 Finuf P, Silva R. Bicycle-related head injury mortality in Texas [abst 225]. Proceedings of the Third International Conference on Injury Prevention and Control 1996:54

26 Mullen P, Hersey J, Iverson D. Health behavior models compared. Soc Sci Med 1997;24:973-81.

27 Macknin ML, VanderBrug-Medendorp S. Association between bicycle helmet legislation, bicycle safety education, and use of bicycle helmets in children. Arch Pediatr Adolesc Med 1994;148:255-9.

28 Gielen AC. The PRECEDE-PROCEDE model's planning model. In: Glanz K, Rimer B, Glanz FM, eds. Health education theory. 2nd Ed. San Francisco, CA: Jossey-Bass, 1997: 359-83.

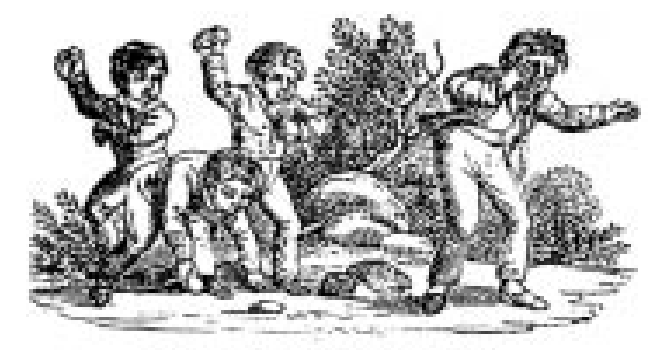

THROWING STONES.

Wicked and malicious boys often tlurner stones, by whith they not only hurt and maim one nnuther, but often kneck out no eye and are alisfigured for life. What a sight is this! We see that one has alrealy received a severe bruise on the face, and is erying in a most ululeful manner, as the blood insbles from the wound. What delight they appear to take in harling the rocky missiles at the wounded boy! What a sight it will be to his parents to sec their son come crying bome, with his face cowered with elotted bloot! If such conduct is so wicked in the sight of men, how much more so must it be in the sight of Нrм who seeth not as man seeth. In winter, the chiliren of ose school sonetimes challenge those of another to combat. Having provided themselves with an abundance of snow and ice balls, and arrayed themselves in order for battle, the contest is commenced and carried ain with great desperation, each one aiming to injure his antagoniat. 